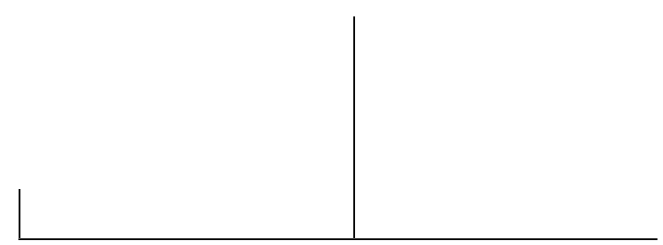

Rev. Latinoam. Psicopat. Fund., São Paulo, 16(2), 208-217, jun. 2013

\title{
A dramática vida de um psiquiatra escritor que abandonou a psiquiatria, mas que a psiquiatria não o abandonou*
}

Héctor Pérez-Rincón

Na extensa lista de médicos escritores (François Rabelais, Anton Chekov, Sir Arthur Conan Doyle, Pío Baroja, Mikhail Bulgakov, Axel Munthe, Louis Ferdinand Céline, Somerset Maugham, Carlo Levi, Bruno Estañol, João Guimarães Rosa etc., etc., etc.) existe um capítulo que poderia intitular-se "Os médicos que oscilaram entre a psiquiatria e a literatura". Devemos destacar, entre esses, três exemplos paradigmáticos que têm em comum haver abandonado a psiquiatria pela literatura em algum momento de suas vidas: Jean Delay, António Lobo Antunes e Oscar Panizza.

O primeiro deles, uma das figuras mais destacadas da psiquiatria do século XX, foi titular da prestigiosa Cátedra de Enfermidades Mentais e do Encéfalo da Universidade de Paris, introdutor da clorpromazina, inaugurando a psicofarmacologia moderna, membro da Academia Francesa, e pôde durante algum tempo conciliar ambas as atividades, publicando ininterruptamente tanto as suas obras psiquiátricas como as literárias - entre as quais se sobressai a sua psicobiografia de André Gide. Após a

*Conferência pronunciada no Laboratório de Psicopatologia Fundamental do Programa de Estudos Pós-Graduados em Psicologia Clínica da Pontifícia Universidade Católica de São Paulo, em 13 de setembro de 2012. 


\section{CONFERÊNCIA}

revolta estudantil de maio de 1968, que teve entre as suas características a crítica feroz contra "os mandarins", Jean Delay, desencantado e magoado, pediu a sua aposentadoria antecipada, abandonou a clínica (que nunca exerceu a prática privada) e se dedicou exclusivamente à escrita. Empreendeu uma pesquisa documental sobre as origens da sua família desde o século XVI e captou uma nova visão da evolução da sociedade francesa ao longo das vicissitudes da história, na série de livros que compõem a coleção "Avant-memoire".

O segundo, sem dúvida um dos escritores contemporâneos mais conhecidos, serviu como médico no exército português durante a sangrenta guerra de Angola e depois do seu regresso a Lisboa exerceu por breve tempo a psiquiatria. Logo a abandonou - basta ler o seu célebre romance "Memória de elefante" para perceber a sua mitigada opinião sobre essa especialidade - para dedicar-se por completo à criação de uma sólida e reconhecida obra literária.

A terceira figura, que evoco à contraluz de seus outros dois colegas admirados e triunfadores, foi um psiquiatra e escritor alemão, hoje esquecido, cuja dolorosa vida expõe múltiplos motivos de reflexão para o especialista contemporâneo. Oscar Panizza nasceu em Bad Kissingen, na Baviera, em 1853 (três anos antes de Kraepelin e Freud), segundo filho de um casal muito singular: o pai, católico, provinha de uma família de pescadores do lago de Como (Lombardia), e a mãe, prolífica escritora, de uma das aristocracias huguenotes que se estabeleceu em Wurzburgo no século XVII. Seus biógrafos assinalam o peso que tiveram em sua vida os conflitos religiosos e a sua constante luta contra a autoridade religiosa. O próprio Panizza reconheceu a importância dos antecedentes psiquiátricos do ramo materno no desenvolvimento da sua personalidade. O pai, descrito como "passional, excêntrico, irascível, homem do mundo e mau administrador dos bens familiares", morreu quando Oscar tinha dois anos, o que explicaria o fato de sua relação com a mãe ter sido tão estreita durante a infância. Recém-viúva, ela pediu às autoridades bávaras a autorização para enviar seus filhos à Prússia para receberem uma educação protestante, o que lhe foi negado. Oscar teve inicialmente dificuldades de aprendizado e era um menino introvertido de imaginação vivaz. Aos 12 anos, coincidindo com o sarampo, apresentou um episódio de sonambulismo, ao que posteriormente atribuiu, em um texto autobiográfico que escreveu em 1904, um significado profético. Aos 17 anos Panizza se mudou para Munique a fim de realizar a sua formação preparatória e, simultaneamente, estudos musicais. Teve dificuldades com a mãe, pois enquanto ela desejava para ele uma carreira eclesiástica, Oscar desejava ser cantor e, além disso, esbanjava o dinheiro que ela enviava nas múltiplas diversões que Munique oferecia. Somente concluiu os seus estudos preparatórios depois de haver cumprido o serviço militar. Aos 24 anos abandonou a música e se inscreveu na Faculdade de Medicina. Dedicou-se 
de corpo e alma ao estudo da medicina e se destacou pela sua obstinação, a ponto de seu orientador de tese, o Professor Von Ziemssen - iniciador da punção lombar com fins de diagnósticos - tê-lo solicitado como assistente. Não abandonou totalmente, porém, a sua vida licenciosa, pois sendo estudante universitário, contraiu sífilis em uma de suas desafortunadas aventuras com prostitutas. A infecção luética se manifestaria depois como uma goma incurável na tíbia direita.

Em 1880 obteve o seu título com a tese Uber Myelin, Pigment und Micrococcen in Sputum e, um ano depois, viajou a Paris com a finalidade aparente de "atualizar os seus conhecimentos médicos", porém além de visitar hospitais se dedicou muito mais a estudar a literatura francesa e a assistir peças teatrais, o que o faria descobrir a sua vocação. Exerceu a psiquiatria durante dois anos como médico assistente no Manicômio de Munique tendo como chefe nada menos do que Johann Bernhard Aloy von Gudden, cuja fama atual se deve tanto ao fato de haver sido o mestre de Emil Kraepelin, como ao dramático final que teve junto ao seu paciente, o rei da Baviera, Ludwig II - o rei louco. As tensas relações que manteve com o seu chefe, associadas aos seus problemas de saúde e ao desejo de se dedicar o tempo todo à literatura, o convenceram de que devia renunciar à sua vida de trabalho hospitalar. Segundo os seus biógrafos, o contato com os pacientes psicóticos e as frustrações de sua vida pessoal o conduziram a um severo quadro depressivo que durou um ano. A criação literária lhe permitiu recuperar e manter durante algum tempo a saúde mental. A primeira obra que Panizza escreveu foi uma poesia, em 1871, dedicada ao cinquentenário de sua mãe - de quem dependeria economicamente durante toda a sua carreira literária. Em 1885 viajou a Londres para estudar durante um ano a literatura inglesa, tendo trabalhado no British Museum. Nessa mesma data publicou o primeiro de uma série de três livros de poesia, com os quais não obteve nenhum reconhecimento. Este chegaria, entretanto, com a sua primeira obra narrativa, Dämmerungsstücke, dedicada a Edgar A. Poe, uma série de relatos ambientados em uma zona intermediária entre o dia e a noite, a realidade e a fantasia, a normalidade e a loucura.

Embora Panizza tenha abandonado a prática psiquiátrica, em 1891 publicou um texto que alcançou a celebridade: Genie und Wahnsinn (Gênio e loucura) que, seguindo as ideias de Lombroso, então muito na moda, abordou com originalidade temas como as alucinações e as suas influências na origem das religiões; as psicoses; e os efeitos da maconha. É bom recordar que estudando em si mesmo os seus efeitos, Joseph Moreau de Tours inaugurou a psiquiatria experimental, e que em sua juventude o próprio Charcot, dedicado nesses anos a inventar a neurologia, havia pertencido ao Club des Hachischins. Nesse mesmo ano de 1891, Panizza começou a chamar a atenção das autoridades e da censura, e a escandalizar os moralistas, quando em Gegen Pruderie und Luge (Contra o puritanismo e a 


\section{CONFERÊNCIA}

mentira) defendeu a natureza sensual da literatura germânica tradicional: "Não se pode dominar o amor, ele é a summa lex e a suprema voluntas. Não se pode regular o amor alemão por um decreto de Postdam" - aonde residia o Kaiser. As coisas se complicaram quando em Das Verbrechen in Tavistock-Square (O crime da Praça Tavistock) descreveu com grande realismo práticas onanistas. A polícia sequestrou a edição e o autor foi levado a julgamento. No ano seguinte publicou em um dos jornais diários mais lidos na Alemanha um artigo sobre a prostituição. Depois de descrever a sua evolução ao longo da história e apresentar a mulher como sedutora e tentadora por natureza, concluía que a prostituição era natural e necessária. Não ocultou a sua simpatia pelas prostitutas e, no artigo, as tratou respeitosamente, ao contrário do habitual na época em seu país. Segundo seus biógrafos, elas foram, ao longo da vida, os seus únicos contatos heterossexuais.

Os problemas com a censura e com a justiça se agravaram quando em 1892 tornou-se mais notória a sua temática anticatólica. Depois da proclamação do dogma da Imaculada Conceição de Maria por Pio IX, publicou uma paródia, "A Imaculada Conceição dos Papas", cuja autoria atribuía a um frade espanhol chamado Martín, aparecendo Oscar Panizza como o tradutor para o alemão (artifício literário que repetia Cervantes com Dom Quixote), e no qual propunha que essa condição se estendesse a todos os papas "com todas as consequências embriológicas, antropológicas e teológicas"... Dois anos depois foi representada a sua primeira obra teatral, Der heilige Staatsanwalt (O sagrado fiscal), na qual une os seus dois interesses maiores: a sexualidade e a religião. Ele encena o julgamento de Lust, uma prostituta, acusada por quatro testemunhas: "Bondade Eterna", "Verdade", "Beleza" e "Moralidade", porém defendida por uma testemunha extraordinária: Martin Lutero, que pronuncia um sermão que arranca aplausos do público. Nesse mesmo ano (prova de que vivia um período muito produtivo), Panizza publicou em Zurique o que seria a sua obra mais conhecida: Das Liebeskonzil ( $O$ concílio do amor), "Tragédia celestial em cinco atos", assinada com o mesmo pseudônimo de sua peça anterior, onde apresenta a origem da sífilis como a vingança de Deus contra as criaturas sexualmente hiperativas, representadas na obra pelos personagens da corte papal de Alexandre VI (Rodrigo Borgia - italianização do hispânico Borja no original), porém com clara referência à sua patologia pessoal. O escândalo acompanhou, desde a sua estreia, esta peça inspirada tanto na história da Igreja renascentista como em um fato crucial da patologia venérea, que surgiu nessa época diante dos médicos: a doença devastadora Morbus galico, o "Mal napolitano", como na quase contemporaneidade do Concílio Vaticano Primeiro convocado por Pio IX. O escândalo se desencadeou não somente porque nela são mostrados com grande realismo os dissolutos costumes da corte papal, 
mas sobretudo porque Deus Pai aparece como um velho decrépito que exibe uma mórbida afetividade por um querubim; Jesus, como uma espécie de idiotinha, eternamente sofrendo e com problemas de fixação edipiana óbvios; e Maria como uma mulher faminta de sexo. O primeiro ato deveria ser concluído com um fumadouro de maconha por parte dos três personagens sacros. A obra foi interditada e o seu autor acusado de ultraje à religião. O processo terminou com a sentença de um ano de prisão e com a destruição das cópias da peça teatral. Panizza foi enclausurado na prisão de Nurenberg e, em seguida, em Amberg, devido à piora de sua lesão sifilítica na perna direita. Sua família pediu que o liberassem do cárcere alegando que ele sofria de um transtorno mental. As autoridades médicas da prisão não consideraram assim. No entanto, era evidente que o ambiente carcerário havia minado tanto a sua saúde física como a sua condição mental. Seus conhecidos o descreveram, após o seu regresso, como uma figura pálida e magra, hesitante, soluçante, em contraste com a sua jovialidade anterior.

Pouco antes de Das Liebeskonzil, Panizza havia publicado um curto romance, Ein Skandalöser Fall (Um caso escandaloso), que haveria de legar a ele o interesse dos sexólogos contemporâneos quando, em 1978, Michel Foucault o ressuscita como o antecedente literário do caso que então se ocupou: "Herculine Barbin, dite Alexine B.", a partir das memórias de um infeliz personagem do século XIX, afetado por alguma forma de pseudo-hermafroditismo, que considerado inicialmente como mulher, e educado de acordo, sofreu um profundo choque existencial ao ver descoberta, no internato de meninas onde ensinava, a paixão física, bem correspondida, que a unia com a bela sobrinha da diretora. $O$ escândalo leva o capelão da instituição a solicitar o exame do médico, o qual certifica a aberração anatômica, o que acabaria por levar à mudança legal de atribuição de sexo. Alexine, convertida em Abel, não suporta a sua nova condição e depois de passar em Paris anos de angustiante solidão e confusão, escreve suas memórias antes de cometer suicídio. O caso foi habilmente utilizado pelo filósofo francês como parte do empreendimento intelectual em que se situa a sua inacabada "História da sexualidade". Foucault reconhece em Panizza um predecessor, que nesse romance de tipo libertino, muito longe do romantismo pessimista do texto de Alexine, mostra como a medicina e a legislação têm arrebatado à Igreja o poder de decidir sobre os corpos e a sexualidade. É graças a Foucault, e a partir da descoberta desse romance, que o interesse por um autor, até então desprezado, tem crescido em vários lugares.

Em outubro de 1896, Panizza abandonou a Baviera e se estabeleceu em Zurique com a intenção de adotar a cidadania suíça. Um importante editor dessa cidade aceitou publicar a segunda edição do Concílio do amor, porém se recusou a dar à luz nesse momento aos diários que o autor havia escrito na prisão de 


\section{CONFERÊNCIA}

Amberg - por outro lado, dois anos depois, Oscar Wilde, outro escritor perseguido por "questões de moral", conseguiu publicar a sua obra A balada do cárcere de Reading. Panizza decidiu então se tornar o seu próprio editor e fundou a Verlag Zuercher Diskussionen (Editorial de Zurique de Debates), além de um jornal cujo título bombástico fala de uma certa tendência megalomaníaca, aonde, sob diversos pseudônimos, se dedicou a publicar artigos cada vez mais bizarros entre eles "Uma discussão psicopatológica de Cristo" e "O porco em seus aspectos poéticos, mitológicos, históricos e culturais". Seus biógrafos coincidem em que os textos de seu período suíço mostram a gradual desintegração mental do autor e o medo que experimentava de estar enlouquecendo. Tentou lutar contra a desorganização que se instalava com a ajuda de seus instrumentos de defesa: a psiquiatria e a literatura. Assim, escreveu "Nero", uma tragédia em cinco atos em que o imperador é descrito como um psicopata, e a Psychopathia Criminalis, cujo irônico subtítulo era: "Instruções para elucidar psiquiatricamente e determinar cientificamente as enfermidades mentais reconhecidas como necessárias pela Corte. Para médicos, leigos, juristas, custódios, funcionários administrativos, ministros etc.", onde afirmava, zombando tanto da justiça como do alienismo, que "a liberdade de pensamento não era senão uma forma de psicose criminal que devia ser absolutamente perseguida em todos os níveis"...

A partir de 1898 foram ficando mais evidentes os elementos de um processo de deterioração. Nesse ano foi expulso da Suíça depois da denúncia de uma prostituta de 14 anos, a quem ele contratou como modelo para realizar fotos desnuda - surge aqui uma semelhança com Lewis Carrol que gostava dessas fotos de ninfetas. Oscar acusou o Kaiser Guilherme II ("a grande pessoa desconhecida") de ser o motor de sua expulsão. Desenvolveu paralelamente um ódio progressivo por tudo que fosse germânico, a ponto de quase abandonar o uso do alemão, preferindo falar francês, que era, strictu sensu, a sua língua materna, a herança da sua origem huguenote. Mudou-se então para Paris. Sua produção literária foi se empobrecendo. Todavia publicou, durante um ano, um jornal fundado em Zurique, mas as assinaturas se reduziram, até fazê-lo desaparecer em 1902. Na capital francesa, onde vivia em um penoso isolamento social e intelectual e em uma progressiva escassez pecuniária, conseguiu publicar - às suas custas - o seu último livro, Parisiana, coleção de poesias em que o elemento paranoico é muito evidente: predominam nelas uma áspera polêmica contra o Kaiser Guilherme II, considerado como o inimigo público da humanidade e da cultura. Este livro foi publicado com uma dedicatória a Michael Georg Conrad (1846-1927), impulsor do movimento naturalista alemão, considerado por Panizza como o pai da literatura alemã moderna, mas o outrora amigo rejeitou publicamente essa dedicatória em prol do politicamente correto. 
A crítica situação econômica de Panizza o obrigou a regressar à Alemanha. $\mathrm{O}$ processo judicial pendente o conduziu à prisão, mas depois de quatro meses de reclusão foi enviado a uma clínica psiquiátrica, que se revelou precisamente o cúmulo do paradoxo e da desonra, pois era aquela onde havia exercido a especialidade. Durante as seis semanas que permaneceu nessa clínica foi diagnosticada uma forma de paranoia crônica. No entanto, pôde sair do seu internamento e obter algum apoio econômico de sua família. Retornou imediatamente a Paris onde a sintomatologia alucinatória auditiva se juntou ao sistema delirante interpretativo. Em seus delírios o governo alemão o espionava continuamente, agora ajudado por detetives franceses, com o propósito de obrigá-lo a contrair matrimônio. Começaram a aparecer as ideias suicidas. A intensificação de sua percepção alucinatória o conduziu de retorno à Alemanha e, em uma ação ambivalente entre consciência e negação de sua patologia, solicitou internamento em um hospital bávaro, porém ao chegar, a princípio se recusou a entrar. Durante três meses viveu isolado de todos e se dedicou exclusivamente a realizar prolongados passeios. Empreendeu uma tentativa de suicídio, que o terror impediu de levar a cabo, estando já sobre a árvore em que se enforcaria. Finalmente, decidiu que era necessária a sua internação e recorreu a um estranho método: saiu às ruas vestido só com o camisolão de dormir. A polícia o deteve e o conduziu ao manicômio. Em 5 de fevereiro de 1905 foi internado voluntariamente. Foi examinado pelo doutor Gudden, o filho de seu antigo chefe, que era agora um dos assistentes de Kraepelin. O parecer do especialista dizia:

O comportamento do doutor Panizza, nos últimos anos, é prova suficiente de que todas as suas ações e atividades têm sido guiadas por delírios sistematizados de perseguição. Como consequência de tais delírios ele tem mudado frequentemente de residência e transformado o seu estilo de vida em um sem-teto fixo, como um vagabundo refugiado, que com trabalhos consegue comer, que vê a todos como inimigos, e que percebe e interpreta todos os fenômenos de uma maneira patológica.

No entanto, o psiquiatra tinha, na realidade, uma clara e aguda percepção de seu próprio estado - a superestrutura crítica que podia se desenvolver em alguns psicóticos inteligentes, segundo os autores alemães -, a ponto de no seu internamento poder escrever, com rigorosa linguagem médica e em terceira pessoa, uma eloquente ficha biográfica que é a sua sucinta história clínica, e que tem sido de inestimável ajuda para os seus biógrafos.

O termo alemão que o doutor von Gudden filho utilizou foi Verrückheit, a "loucura sistematizada", descrita por Griesinger. O especialista apresentou o mesmo diagnóstico em que o seu pai havia se baseado no parecer pericial que provocou anos atrás, em 1886, a destituição do rei Ludwig da Baviera. Este infeliz 


\section{CONFERÊNCIA}

monarca, protetor de Richard Wagner, havia demonstrado, como se sabe, uma forte oposição às ambições do Reino da Prússia, que levariam à criação do Império Alemão. Quando Panizza toma o Kaiser Guilherme como tema de seus delírios persecutórios, segue de certo modo a atitude de seu antigo monarca. Aqui podemos estabelecer, no caso de Oscar Panizza, uma série de dualidades.

Por um lado, as dualidades da sua própria vida: medicina/literatura; catolicismo/protestantismo; Itália/França; língua alemã/língua francesa; psiquiatria/psicose. Depois, as dualidades do seu entorno: Baviera católica/Prússia luterana; Ludwig II/Wilhelm II; von Gudden pai/von Gudden filho. Finalmente, as dualidades da sua atmosfera psiquiátrica: Verrükheit/Paranoia; Dementia Praecox/parafrenia; Griesinger/Kraepelin. Do ponto de vista nosográfico, é preciso recordar que na sexta edição de seu tratado, em 1899, Kraepelin havia adotado como critérios a evolução e a presença de atividade alucinatória, ao propor a separação dos delírios sistematizados não alucinatórios que evoluem sem lesão das faculdades intelectuais, e os delírios alucinatórios que evoluem em direção a um colapso mental. Aos primeiros reservou o termo de paranoia, e qualificou os segundos como paranoides, considerando-os como um subgrupo da nova identidade: a Dementia Praecox. Não deixa de chamar a atenção que o assistente de Kraepelin ignorara esta nova classificação e seguira utilizando a que seu pai usara há 19 anos.

Em 1921, na oitava edição, o mestre de Munique utiliza precisamente o caso de seu colega escritor, que tinha morrido naquele mesmo ano, para exemplificar o conceito de "parafrenia sistematizada". É possível acreditar que, em sua hospitalização e progressiva deterioração, Panizza não tenha seguido a evolução da nosografia nas sucessivas edições do tratado de seu célebre condiscípulo.

Há um fato pouco conhecido que é de grande interesse para a história da arte e da psicologia da expressão. Ao final da Primeira Guerra Mundial, entre 1917 e 1918, o pintor expressionista George Grosz produziu uma obra perturbadora, realizada com a técnica da colagem, conhecida indistintamente como "Homenagem a Oscar Panizza" ou "Os funerais do poeta Oscar Panizza", apesar de que esse, como já foi dito, morreria apenas três anos mais tarde - apesar de que o seu longo confinamento bem pode ser considerado como uma morte em vida. A pintura, cuja cor dominante é um vermelho sangue, representa uma procissão alucinante de figuras desumanizadas. As três figuras do primeiro plano simbolizam a sífilis, o alcoolismo e a doença, enquanto que a única figura que apresenta características identificáveis é, paradoxalmente no caso do defunto homenageado, um eclesiástico. A morte parece triunfar no centro da composição, que expressa muito bem a temática do autor: o horror da guerra e o colapso da moral. Esta visão da loucura da raça humana lembra Hieronymus Bosch e Peter Bruegel. Simboliza também, em sua estrutura caótica, a desagregação mental. Há 
semelhanças profundas nas biografias do pintor e do psiquiatra escritor. Ambos foram alemães antigermânicos que renunciaram ao uso da sua língua materna: o médico escolheu o francês e o pintor o inglês. Este trocou o Georg original por Georges e o 'ss' final do seu sobrenome por 'sz'. Grosz também sofreu uma internação psiquiátrica antes de emigrar para os Estados Unidos e também foi acusado, pelo tema de sua criação, de "ofensas ao pudor" e de "vilipendiar a religião". Havia, assim, vários motivos para que o pintor sentisse simpatia e ainda uma certa identificação com o escritor. O repúdio à língua alemã, como uma forma de oposição ao belicismo prussiano, tem um certo caráter profético, pois parecia anunciar, em ambos os rebeldes quase anarquistas, a tragédia de seu país natal, quando o idioma que havia transmitido tanta poesia e alta filosofia haveria de se perverter com os discursos do Mal e do Horror.

Se o nome de Panizza tem merecido algumas linhas nos dicionários teatrais e $O$ concílio do amor costuma ser representado de vez em quando, ainda que em meio a uma indignação geral, para a psiquiatria o personagem caiu no esquecimento. Um resgate tardio foi a sua inclusão na recente obra sobre a história do Instituto Psiquiátrico de Munique, escrita pelo professor Hans Hippius, o sucessor de Kraepelin, que o inclui entre os demais alunos de von Gudden. Isto equivale a reconhecer que, apesar de haver abandonado a prática clínica por causa do seu interesse literário e dos seus complicados transtornos emocionais, Herr Doktor Panizza seguiu sendo um especialista em doenças mentais. "Sacerdos in aeternum" diz a frase em latim. Podemos aplicá-la sem ironia a este grande sacrílego.

Oscar Panizza morreu no hospício psiquiátrico próximo a Bayreuth, em 28 de setembro de 1921. Alguns biógrafos asseguram que ao longo desses anos escreveu uma grande quantidade de páginas que repousam em um arquivo esquecido, esperando serem descobertas por pesquisadores curiosos. Outros garantem que ele somente se ocupou com traduções. E alguns afirmam que a sua pena parou para sempre. Com uma abordagem de antipsiquiatria desatualizada, alguns autores têm proposto inclusive que este prolongado confinamento foi o castigo que o poder que ele criticou lhe impôs por sua temática blasfema e irreverente. A longa noite dessa internação deixa dúvidas sobre a etiologia da grave deterioração do psiquiatra escritor. Sofreu a debilitação progressiva que ocorria ao final dos quadros de "loucura sistematizada", segundo Griesinger? Foi um dos mais brilhantes cérebros desse século conduzido pela sífilis à trágica noite de demência? Ou seria, talvez, como apresentou em $O$ concílio do amor, que essa enfermidade sexualmente transmitida foi, com efeito, a metáfora da vingança de um deus contra as suas criaturas sexualmente hiperativas? Seja lá como for, um ano depois da anônima morte deste psiquiatra escritor, faleceu em Paris, coberto de 
glória, Marcel Proust, autor de uma das obras mais portentosas da literatura, considerada pelo psiquiatra italiano, Professor Romolo Rossi, diligente conhecedor das letras (o médico que resgatou Ezra Pound da prisão norte-americana) como "o maior tratado de Psiquiatria jamais escrito". Proust nos oferece outra chave para entender Panizza (e muitos outros mais):

Qual o médico de loucos que não terá tido, à força de assisti-los, a sua crise de loucura? Feliz ainda se pode afirmar que não se trata de uma loucura anterior e latente que o tivesse feito dedicar-se a eles. O objeto de seus estudos, por um psiquiatra, muitas vezes age de novo sobre ele. Mas antes disso, esse objeto, que obscura inclinação, que terror fascinante o fizera escolhê-lo? (La Prisonnière).

\section{Héctor Pérez-Rincón}

Professor de psicopatologia nos cursos de pós-graduação e psiquiatria da Universidad Nacional Autónoma de México (México, D.F.); Membro da Academia Nacional de Medicina e do Instituto Nacional de Psiquiatría Ramón de la Fuente (México, D.F.).

Calz. México-Xochimilco 101

Col. San Lorenzo Huipulco

Deleg. Tlalpan 14370 México, D.F.

e-mail:perezrh@imp.edu.mx 